Motrivivência $\quad$ v. 26, n. 43, p. 133-149, dezembro/2014

http://dx.doi.org/10.5007/2175-8042.2014v26n43p133

\title{
EDUCAÇÃO FÍSICA E A REDE DE SAÚDE PÚBLICA: dilemas, possibilidades e desafios entre a formação e a intervenção
}

\author{
Márcia Fernanda de Méllo Mendes \\ Marielly de Mornes² \\ Sabrina Chapuis de Andrade ${ }^{3}$ \\ Cristianne Maria Famer Rocha ${ }^{4}$
}

\section{RESUMO}

O objetivo desta pesquisa foi identificar e analisar as atividades realizadas pelos profissionais de Educação Física (PEF) nos serviços da rede pública de saúde. Metodologia: utilizou-se a técnica de Grupo Focal com a participação de onze PEF. Resultados: verificou-se que os PEF, a partir do vivido por estes profissionais, ingressam nos serviços de saúde sem conhecerem previamente a área de atuação, que não reconhecem as ferramentas que a graduação lhes ofereceu para o trabalho e acreditam que o cotidiano do trabalho ou formação pós-graduada foram as estratégias que lhes deram competências para o trabalho no SUS. Considerações: A pesquisa identificou que

1 Especialista em Saúde Mental, Gestão Participativa e Políticas Publicas em Saúde, Práticas Pedagógicas em Serviços de Saúde. Docente de Educação Física do IFRS. Bento Gonçalves/Rio Grande do Sul, Brasil.

E-mail: marciafmm@yahoo.com.br

2 Mestre em Ciências do Movimento Humano. Docente no curso de Fisioterapia FEEVALE. Novo Hamburgo/Rio Grande do Sul, Brasil.

E-mail: mariellydemoraes@yahoo.com.br

3 Especialista em Saúde Mental, Práticas Pedagógicas em Serviços de Saúde e Saúde da Família. Servidora Pública na FMSC. Estancia Velha/Rio Grande do Sul, Brasil.

E-mail: sabrinachapuis@gmail.com

4 Doutora em Educação. Docente da UFRGS. Porto Alegre/Rio Grande do Sul, Brasil.

E-mail: sabrinachapuis@gmail.com 
há uma lacuna entre a formação do PEF e a realidade da prática profissional que atenda às diretrizes e necessidades do SUS. A formação deve superar o modelo hegemônico biológico, centrado puramente da técnica, propondo uma reflexão crítica da realidade e uma nova concepção de saúde, sociedade e de sujeito.

Palavras-chave: Educação Física; Atenção à Saúde; Competência Profissional

\section{INTRODUÇÃO}

Este artigo é resultado de uma pesquisa realizada no ano de 2012 com os Profissionais de Educação Física (PEF) que atuam na rede pública de saúde no Rio Grande do Sul. O estudo buscou compreender suas intervenções nos serviços de Saúde Pública e como a formação profissional tem contribuído para que a práxis dialogue com os princípios e diretrizes do Sistema Único de Saúde (SUS). (TRECHO RETIRADO)

A partir dos anos 2000, há uma crescente demanda por PEFs em serviços de Saúde Pública como nos Centros de Atenção Psicossocial (CAPS), em Núcleos de Saúde da Família (NASF) e nas Academias da Saúde. Outra porta de entrada da Educação Física, no SUS, foi através da proliferação das Residências Multiprofissionais em Saúde, que oportunizam e oferecem uma formação especializada na área de Saúde Mental, Atenção Básica, Saúde do Idoso, entre outros. A Residência Multiprofissional em Saúde caracteriza-se por uma formação em serviço, com duração de dois anos e dedicação exclusiva. Devido ao convívio multidisciplinar e multiprofissional, em muitos casos, as certezas inerentes à formação acadêmica fazem emergir questões acerca do papel profissional: (TRECHO RETIRADO) será que o fazer da Educação Física na Saúde Mental ou na Atenção Básica é o mesmo fazer da Educação Física no fitness ou na educação? Faz sentido os princípios da vida ativa para este público? O que os PEF estão fazendo no espaço da Saúde Mental ou da Atenção Básica e podem contribuir para uma melhor a qualidade de vida das pessoas?

Quando se fala em Saúde Mental, entende-se os serviços destinados a pessoas portadoras de transtornos mentais, tem como carro chefe os CAPS, um centro multiprofissional (médico, enfermagem, psicólogo, assistente social, terapia ocupacional, PEF, entre outros profissionais) que oferece atendimento diário para pessoas com transtornos mentais graves e persistentes que pode ser de forma intensiva, semi-intensiva e não intensiva (BRASIL, 2004). Cada pessoa atendida deve ter seu Projeto Terapêutico Singular (PTS) que engloba tanto as intervenções individuais, como intervenções no meio que está inserida. O termo Atenção Básica, aqui no Brasil, é utilizado como sinônimo de Atenção Primária em Saúde que é uma estratégia de organização de atenção a saúde voltada aos indivíduos e comunidades, com ações preventivas e curativas. Ela dá-se a partir da institucionalização de serviços locais de saúde, centrados nas necessidades das pessoas e em uma prática interdisciplinar (MATTA, MOROSINI, 2009).

No trabalho no SUS, cabe aos profissionais reforçarem diretrizes como 
interdisciplinariedade, intersetorialidade, educação popular, território, integralidade, controle social, educação permanente em saúde, promoção de saúde e humanização nas diversas áreas estratégicas do Sistema (BENEDETTI; BORGES, 2014)

Tendo como inspiração os questionamentos citados anteriormente, realizou-se uma pesquisa que abordou o tema da intervenção do PEF na rede pública de saúde, a partir da percepção dos próprios profissionais inseridos neste contexto de atuação. $\mathrm{O}$ objetivo principal foi identificar e analisar as atividades realizadas pelos PEF, assim como investigar a intencionalidade nas atividades propostas e como a formação profissional influencia na intervenção profissional.

Para tanto, foi utilizada a técnica de Grupo Focal com PEF que teve como eixo norteador para discussão a formação profissional e a intervenção do profissional. Para a análise dos dados, empregou-se a análise de conteúdo, segundo Bardin (2004), com a construção de categorias analíticas.

\section{A Educação Física como profissão}

A Educação Física (EF) é a ciência que trata do movimento humano tendo entre seus elementos: ginástica; exercícios físicos; desportos; jogos; lutas; capoeira; artes marciais; danças; atividades rítmicas, expressivas e acrobáticas; musculação; lazer; recreação; reabilitação; ergonomia; relaxamento corporal; ioga; exercícios compensatórios à atividade laboral; além do cotidiano e outras práticas corporais (CONFEF, 2002).

O movimento é nato ao ser humano, sendo que nas civilizações antigas a sobrevivência dependia das atividades físicas. Além disso, tinha-se a dança que tanto era utilizada em rituais, como em atividades lúdicas. À medida que o homem muda seu estilo de vida, sedentarizando-se, a atividade física passava a ter outro papel no cotidiano (OLIVEIRA, 1983).

No século XIX, surgiram as quatro principais correntes da Educação Física: a alemã - a ginástica como dever da vida humana; a nórdica - ginástica para elevar a moral do povo e preocupava-se com a execução correta dos exercícios; a francesa - com marcante espírito militar e exerceu uma influencia importante a Educação Física brasileira e a inglesa - tinha uma orientação não ginástica, o esporte tinha uma conotação pedagógico-social (OLIVEIRA, 1983).

De acordo com Gancz (2006) no Brasil, a Educação Física apresentou algumas tendências, transitando por concepções vinculadas com a saúde, o civismo, a política, o rendimento, e inclusive, o social, considerando uma visão hegemônica da época. Percebe-se nestas tendências disputas ideológicas que acompanham os ideais de sociedade, como cita Brach (1999) a EF pode reproduzir os valores e princípios da sociedade capitalista industrial moderna ou produzir sujeitos que poderão agir de forma autônoma e critica na esfera da cultura corporal ou de movimento tendo um papel político e transformador da sociedade.

Neste cenário que, na atualidade, tem-se um marco importante que é a regulamentação profissional através da Lei $\mathrm{n}^{\circ} 9696$ de $1^{\circ}$ de setembro de 1998 (BRASIL, 1998). A partir desta, outras resoluções foram instituídas, como o Código de Ética do Profissional de Educação Física - Resolução CONFEF no 056/2003 (CONFEF, 2003); e a Intervenção do Profissional de Educação 
Física Resolução CONFEF no 046/2002 (CONFEF, 2002) - estabelecendo práticas e a categorização da profissão entre graduado e provisionado, bacharel e licenciado.

Com a regulamentação da profissão passaram a existir duas categorias profissionais: os graduados que possuem diploma obtido em curso de EF, oficialmente autorizado ou reconhecido; e os provisionados, referente a quem já exercia a profissão por no mínimo três anos antes da vigência da Lei 9696/98. Ambas as categorias são submetidas ao Conselho Federal de Educação Física (CREF, 2012). De acordo com formação profissional, ainda há a diferenciação entre a licenciatura e o bacharelado, instituídas pelo Conselho Nacional de Educação (CNE), por meio da Resolução 1, de 18 de fevereiro de 2002 e Resolução 7, de 31 de março de 2004 (STEINHILBER, 2006).

Nos documentos acima citados, a EF é conceituada como um conjunto de atividades físicas e desportivas, componente curricular obrigatório, e também uma profissão designada a atender às demandas sociais referentes a atividades físicas nas suas diferentes manifestações, na conquista de um estilo de vida ativo.

De acordo com o CONFEF, 2002, como intervenção, a EF utiliza diagnóstico, procedimentos, ministra aulas, orienta, desenvolve, identifica, planeja, coordena, supervisiona, leciona, assessora, organiza, dirige e avalia as atividades físicas, desportivas e similares, devendo atender a diversas expressões do movimento humano, considerando o contexto social, histórico cultural e territorial. Como especialista no conhecimento da atividade física/ motricidade humana, o PEF pode atender de forma individual, coletiva, em equipes multiprofissionais e interprofissionais.

\section{Percurso Metodológico}

Para a pesquisa foram realizados dois Grupos Focais com um total de onze profissionais que atuam na rede pública de saúde. Os grupos focais tiveram duração de aproximadamente uma hora. Cinco PEF participaram do primeiro grupo (A) e seis do segundo (B). Fez-se essa escolha metodológica considerando que não existiam muitas pesquisas sobre o tema, e também pela possibilidade de propiciar um espaço coletivo de interação potencializador de produção de novos saberes, para que, além de fornecer informações para a pesquisa propriamente dita, o grupo pudesse trazer outros desdobramentos e benefícios aos participantes, como a troca de experiências.

Para iniciar esse processo, após aprovação no Comitê de Ética em Pesquisa em Saúde da Escola de Saúde Pública do Rio Grande do Sul (ESP/RS), foi feita a divulgação da pesquisa junto aos PEF. Definiu-se como população os profissionais de EF que estivessem vinculados aos serviços da rede pública de saúde. A amostra foi escolhida de forma intencional; o convite para participar da pesquisa foi por conveniência, a partir de contatos por e-mail e telefones institucionais, da divulgação e convites em redes sociais. Para este estudo foram considerados os seguintes critérios de inclusão: ser PEF com diploma obtido em Curso de Educação Física reconhecido pelo MEC; estar vinculado a algum serviço da rede de saúde pública, e ter disponibilidade e desejo de participar da pesquisa. 
Realizou-se pesquisa no DATASUS 5 buscando os PEF cadastrados no Cadastro Nacional de Estabelecimentos de Saúde (CNES), considerando as diversas denominações do Código Brasileiro de Ocupações (CBO). No processo de busca no DATASUS, encontrou-se 154 PEF em serviços vinculados ao SUS no Estado do Rio Grande do Sul, distribuídos em centros de atenção psicossocial, unidades de saúde, centros de saúde, núcleos de apoio à saúde da família, hospitais, consultórios de rua e serviços de reabilitação.

Nos contatos realizados para convidar os PEF a participarem da pesquisa, obteve-se retorno de vinte profissionais; destes, onze puderam participar dos grupos focais, o restante não preencheu os critérios de inclusão, quais sejam, estar no momento vinculado a um serviço de saúde pública ou ter disponibilidade de participar dos grupos focais nos horários estabelecidos.

O Grupo Focal tem por característica identificar e possibilitar a tomada de consciência sobre um tema, utilizando a tendência humana de formar opiniões e mudar de atitude na interação com o outro (Lervolino e Pelicioni, 2001), a escolha por utilizar tal técnica de busca de informações foi feita em função do desenho da pesquisa e da população. Esta técnica é direcionada para um pequeno número de pessoas, de
4 a 12 indivíduos com características comuns, que possam divergir, opinar, tendo como objetivo investigar experiências pessoais e revelar as percepções dos participantes sobre os tópicos em discussão (DIAS e ROCHA, 2009).

Para a realização do grupo, contou-se com um moderador no intuito de criar um ambiente favorável para que os participantes expressassem livremente suas ideias, promovendo o debate. O moderador apresentava implicação com o tema, já que tem experiência na área. No entanto, teve o cuidado de não expressar sua opinião, atentando apenas para que o grupo não desviasse do tema durante a discussão e explorando, através de questões, as falas dos participantes. Também, participaram dois colaboradores, com o papel de anotar as observações, sinais não-verbais e outras ocorrências no grupo. Outro recurso utilizado foi a gravação em áudio das falas, que posteriormente foi transcrita para a análise e categorização dos resultados.

\section{Primeiros Apontamentos}

Houve diversidade do perfil dos PEF envolvidos na pesquisa, tanto em relação à faixa etária, quanto ao tempo de graduados, conforme refere o quadro abaixo:

5 DATASUS é o Departamento de Informática do SUS, ele disponibiliza informações da situação sanitária do país. Uma das seções é o Cadastro Nacional de Estabelecimentos de Saúde (CNES), que disponibiliza informações sobre equipamentos, serviços e profissionais, tanto do sistema público como do privado. 
Tabela 1: perfil dos PEF da pesquisa (MENDES, 2013)

\begin{tabular}{|c|c|c|c|c|c|c|}
\hline Identificação3 & $\begin{array}{l}\text { Faixa Etária } \\
\text { (Anos) }\end{array}$ & $\begin{array}{c}\text { Tempo de } \\
\text { Graduação } \\
\text { (Anos) }\end{array}$ & $\begin{array}{l}\text { Residência } \\
\text { em Saúde }\end{array}$ & $\begin{array}{l}\text { Perceptor/Tutor } \\
\text { em Residências }\end{array}$ & $\begin{array}{c}\text { Outra } \\
\text { Especialização }\end{array}$ & $\begin{array}{c}\text { Tempo } \\
\text { Experiência4 } \\
\text { (Anos) }\end{array}$ \\
\hline S1A & $41-50$ & mais de 25 & não & Sim & Não & aprox. 14 \\
\hline $\mathrm{S} 2 \mathrm{~A}$ & $21-30$ & 01-05 & $\begin{array}{c}\text { em } \\
\text { andamento }\end{array}$ & Não & Não & aprox. 1 \\
\hline S3A & $41-50$ & mais de 25 & não & Sim & Sim & aprox. 27 \\
\hline S4A & $21-30$ & 01-05 & $\begin{array}{c}\text { em } \\
\text { andamento }\end{array}$ & Não & Não & aprox. 2 \\
\hline S5A & $21-30$ & $06-10$ & $\begin{array}{c}\text { em } \\
\text { andamento }\end{array}$ & Não & Sim & aprox. 3 \\
\hline S6A & $21-30$ & 01-05 & não & Não & Não & aprox. 1 \\
\hline S7B & $21-30$ & 01-05 & não & Não & Não & aprox. 2 \\
\hline S8B & $21-30$ & 01-05 & $\operatorname{sim}$ & Sim & Não & aprox. 3 \\
\hline S9B & $21-30$ & 01-05 & $\begin{array}{c}\mathrm{em} \\
\text { andamento }\end{array}$ & Não & Não & aprox. 1 \\
\hline S10B & $51-60$ & mais de 25 & não & Não & Sim & aprox. 4 \\
\hline S11B & $31-40$ & 01-05 & $\operatorname{sim}$ & Sim & Não & aprox. 7 \\
\hline
\end{tabular}

Em relação à titulação, nenhum dos participantes tinha mestrado ou doutorado. Sobre a formação em residência em saúde, participaram quatro egressos de Residência em Saúde Mental, um estava cursando Residência em Saúde do Idoso e outro da Residência em Atenção Básica. Predominou a formação e experiência profissional em saúde mental, o que provavelmente se dá pelo tempo de existência da Residência Integrada em Saúde Mental da Escola de Saúde Pública do Rio Grande do Sul. Quanto aos PEF que exerciam preceptoria/tutoria, participaram um profissional vinculado à Residência em Saúde Mental e outro à Residência em Saúde Mental e Atenção Básica.

Considerando a vinculação e experiência profissional, quatro participantes eram provenientes de Centros de Atenção Psicossocial (CAPS); um de Hospital Psiquiátrico; dois de unidade de internação em Hospital Universitário; um de Residências Terapêuticas; dois de Núcleo de Apoio à Saúde da Família (NASF) e um de CAPS e NASF.
Os participantes se mostraram sensíveis à temática, e abertos à discussão. Inicialmente os PEF se apresentaram ao grupo e contextualizaram sua inserção na rede pública de saúde. A partir das falas iniciais, os participantes, instigados pela moderadora, abordaram assuntos referentes à formação profissional, aos processos de trabalho, ao processo histórico da EF e às atividades realizadas pelos EF, considerando a diversidade das experiências do grupo.

Como metodologia de análise dos dados foi utilizada a análise de conteúdo, caracterizada como uma série de técnicas com a intenção de buscar o sentido ou os sentidos de um documento (CAMPOS, 2004). Trata-se de um "conjunto de técnicas de análise da comunicação que utiliza procedimentos sistemáticos e objetivos de descrição do conteúdo das mensagens comunicação" (BARDIN apud CAMPOS, 2004, p. 612). Nesta técnica de análise, observa-se além do escrito, parte da realidade concreta dos indivíduos e o contexto de sua inserção no grupo e no tema da pesquisa. 
Como resultado da pesquisa, obteve-se quatro categorias: trajetórias, sujeitos e intersecções; formação profissional; intervenção profissional e residência multiprofissional em saúde. Neste artigo são abordadas apenas as categorias que apresentam interface com a formação profissional como trajetórias, sujeitos e intersecções e formação profissional. Para composição das categorias as falas dos dois grupos foram transcritas e depois analisadas, comparadas. As falas foram agrupadas pelo tema, considerando a discussão do grupo, o consenso e o que se destacou na conversa pela sua singularidade.

Para nomear cada PEF participante utilizou-se a identificação no texto como [PEF1A], [PEF2A], [PEF3A] e assim por diante.

\section{Trajetórias, profissionais e intersecções}

(TRECHO RETIRADO) Os PEF desta pesquisa traçaram caminhos distintos que os levaram ao mesmo lugar, o de profissionais que tem em comum a atuação em serviços da rede pública de saúde. Alguns sabendo mais, outros menos sobre o SUS, suas diretrizes e princípios; no entanto, todos utilizando ferramentas que encontraram na formação para desenvolver sua prática cotidiana. Uma das intersecções entre estas trajetórias foi a inserção na saúde pública, que teve início de formas diversas: por acaso, por convite de um colega, por um projeto novo que estava iniciando, por um estágio curricular ou extra-curricular, ou por uma oportunidade de especialização.

Para a maioria dos integrantes dos grupos o primeiro contato com a área da saúde pública se deu por meio de estágios durante o período da graduação. Outros participantes se vincularam à área da saúde por convite; eram concursados nos municípios e na implantação de um novo projeto passaram a compor as equipes.

As falas a seguir ilustram essa questão:

Minha primeira aproximação foi com um colega quando ele estagiava no CAPS do Hospital de Clinicas, ele estava saindo, finalizando o período de estágio e me indicou. Eu fiquei. Trabalhar com saúde mental, nunca tinha ouvido falar nada, nem da possibilidade do professor de EF trabalhar com isto. E aí aceitei; assim, pedi pra ele algumas leituras e ele me mandou e, eu pensei: este troço de SUS parece bacana. [PEF4A]

Há uns quatro anos atrás começaram a trabalhar com os NASF e queriam colocar a atividade física, não tinha ninguém que assinasse pelos estágios, que ficasse como supervisor dos estagiários. Me convidaram e eu fui. [PEF10B]

Me chamaram porque acharam que meu perfil era interessante pra participar de uma seleção na SMED porque a saúde precisava de um representante (...) pra compor uma equipe que faria o atendimento integral à criança e adolescente em situação de rua (...) fui então selecionada pra compor (...) do grupo que trabalhou alguns saíram, enfim, eu permaneci (...) mas ai peguei a transformação pra CAPS. [PEF1A] 
Em geral, os profissionais não sabiam o que encontrariam no campo de atuação da saúde pública. A desacomodação dos PEF pareceu um sentimento comum, embora viesse como um desafio pelo encontro com o novo.

Ao refletir sobre como cada PEF chegou neste ponto comum que é a intervenção na rede pública de saúde, pode-se inferir que a eventualidade não é algo a toa, demonstra o quanto a formação acadêmica não tem acompanhado a ampliação dos campos de atuação da profissão.

A formação profissional passou por reformulações curriculares para dar conta do novo perfil que necessita ter o PEF; entretanto há uma sensação de não se ter avançado de acordo com a necessidade, conforme descreve Verenguer (2004), uma vez que as alterações respondiam a necessidades das ciências-mães e a suas subdisciplinas como anatomia, fisiologia, biomecânica e aprendizagem motora, dentre outras; as quais não necessariamente contribuíram para instrumentalizar a intervenção profissional na rede pública de saúde em consonância com os princípios e diretrizes do SUS.

Tendo em vista que a EF nos SUS é um contexto ainda novo, pode-se dizer de um "não lugar" que serviços como NASF (o fazer cotidiano como equipe de NASF é um desafio para todas as profissões). Contudo, a inserção em equipes de Saúde Mental acontece há décadas, até antes do SUS, e ainda continua sendo uma surpresa para os estudantes de graduação no que tange a possibilidade de estágio e intervenção em serviços como CAPS e serviços de Saúde Mental.

Quando eu me deparei no tempo da graduação, que foi inicio da década de 80, não existia SUS. O SUS veio lá em 88, eu já era funcionária do hospital psiquiátrico (...) pra que isto chegue no trabalhador leva muito tempo, né (...) como se operacionaliza isto na prática tem uns distanciamentos enormes. E agora, se não houver uma mudança curricular... e que eu saiba, recém este ano na UFRGS houve uma mudança no seu currículo incluindo a saúde coletiva. [PEF3A]

O tema da formação acadêmica esteve muito presente nas discussões, sendo trazido como justificativa para práticas que não dialoguem com as necessidades de saúde da população e também, como uma ferramenta importante para mudança de perfil profissional para o futuro.

Ao falar de um "não lugar" da EF na Saúde Pública pode-se pensar em duas perspectivas, uma que assusta e outra que desafia. Assim os profissionais que se inserem nos serviços vão adotando posturas profissionais diferenciadas, uns reproduzem práticas conhecidas como as realizadas em clubes, academias e até em escolas. Outros percebem como um desafio e um campo fértil para muitas possibilidades, um novo fazer centrado na escuta, na clínica ampliada, no PTS, enfim, uma atenção centrada em um sujeito integral.

\section{A formação profissional e a graduação em Educação Física}

Como afirma Tani (2007) a formação é um processo complexo e dinâmico e deve considerar diversos fatores como a 
necessidade social, de mercado de trabalho, estrutura, docentes, conhecimentos, proposta do curso e discentes. Quando se fala de formação profissional em EF, estamos diante de ao menos três possibilidades de certificação: a licenciatura plena (formação mais antiga), a licenciatura, e o bacharelado, de acordo com as Diretrizes Curriculares Nacionais vigentes.

A identidade profissional é uma questão histórica na formação da EF. Nas décadas de 70 e 80 , houve crises marcantes que geraram muitas discussões sobre currículo e qual perfil profissional estava se formando (TOJAL, 2005). Como resultado disto, foi instituída a Resolução CFE nº 03/87, após várias proposições, reavaliações e análises:
A Resolução CFE no 03/87, é que objetivava oportunizar que os Cursos de Graduação em Educação Física do País pudessem proceder a alterações profundas na formação profissional por eles oferecida, para o que estabelecia: Inicialmente que em lugar do Currículo Mínimo, definido praticamente como jurisprudência de padrão obrigatório pelo CFE até então, passasse a existir a liberdade das Instituições superiores de Ensino pela definição de seus próprios projetos, agora não mais apoiados em um rol de disciplinas e/ou matérias, mas sim em área do conhecimento, como: cunho humanístico (ser humano, sociedade, natureza) e cunho técnico, que abordaria todas as condições técnicas e tecnológicas do campo profissional, bem como permitindo que por interesse e responsabilidade próprias, procurasse buscar resolver questões e peculiaridades regionais e, assim pudesse propor a formação de profissionais com perfis diferenciados. (TOJAL, 2005, p. 30)

Fiz minha formação no IPA, foi bem interessante, porque na época a UFRGS estava com uma linha de treinamento desportivo. [PEF1A]

Apesar de ter tido muito pouca vivência na faculdade com idoso, porque o currículo não proporciona isto, pelo menos na PUC, não sei como é que é na UFRGS, no IPA; mas na PUC a gente tem uma vivencia muito pouca nessa área do idoso. [PEF2A]

Eu sou da PUC também, me formei há 10 anos (...) fiz uma graduação que não tem nada a ver, não vou dizer nada porque é obvio que a gente traz muitas coisas, mas assim, didaticamente falando ou pensando no currículo, sabe, eu não estaria fazendo o que eu faço. [PEF5A]

Outra questão que surgiu com relevância nos grupos focais foi a relação entre a teoria e a prática e como transpor o conhecimento aprendido nas instituições de ensino para a intervenção profissional. As falas a seguir disparam a reflexão:

Na época da faculdade a gente pensava muito nisto, o que estamos aprendendo aqui não tem nada a ver com a escola que eu estou lá. [PEF1A] 
Pensar uma $E F$, enquanto hoje (...) como é que isto se relaciona, como é que vou articular isto no serviço público, tendo em vista a necessidade que as pessoas têm e não aquilo que eu posso oferecer. A oficina do futebol, a oficina do esporte, mas será que as pessoas querem isto? Tem esta necessidade? [PEF3A]

No início do estágio curricular eu ia pra oficina (...) muito com esta questão do professor da escola que vai com um objetivo, um planejamento, e que daqui a pouco me dei conta que não era aquilo. [PEF7B]

Verenguer (2004) relata que a cientificização sofrida pela EF na década de 80/90 não contribui para a intervenção profissional, havendo um distanciamento entre as pesquisas e o cotidiano profissional. Também não rompeu com a dualidade em que se estabelecia teoria x prática. A dualidade de conceitos é uma constante da área, presente em concepções de corpo x mente, pensar $\mathrm{x}$ fazer, teoria $\mathrm{x}$ pratica. A necessidade de romper com estas dicotomias já foi superada; todavia a mudança de cultura é um processo lento, e a contraposição das concepções se mostra, muitas vezes, de forma subliminar, mascarando o entendimento real que se tem da profissão.

Para definição de prática, encontramos no dicionário descrições como: "1. Ato ou efeito de praticar; 2 . Uso, experiência, exercício; 3. Rotina; hábito; 4. Saber provindo da experiência técnica; 5. Aplicação da teoria" (AURELIO, 2004). É notória a inter-relação que os conceitos apresentam, e a necessidade do currículo de proporcionar uma formação com ferramentas que transponham o conteúdo, que seja uma formação crítica e reflexiva que desenvolva a autonomia profissional.

É importante perceber que a atuação do PEF não é apenas a aplicação de saberes, mas também de produção, transformação e mobilização desses saberes. Freire, Verenguer e Reis (2002), Andrade, Costa, Garcia e Florindo (2014) apontam para uma profissionalização que capacite os estudantes a reconhecer, identificar as características e necessidades, as possibilidades e os desejos que se referem ao movimento humano.

Já Darido (1995) critica a formação da $E F$, referindo que ela é acrítica, com ênfase na formação esportiva, ligada ao rendimento e aos mais habilitados, formando profissionais na perspectiva do saber fazer para ensinar. Embora essa crítica seja da década de 90, ele ainda surge como pauta. Podemos verificar nas discussões do grupo focal citadas anteriormente e na fala a seguir:

A educação física não pode ficar restrita a isto, eu acho que a gente tem que pensar numa reformulação curricular em nível de graduação (...) surgiram outras instituições formadoras pra além da ESEF UFRGS, houve uma atualização e surgimento de outras áreas, que a educação física parece que não acompanhou. [PEF3A] 
A problemática da formação acadêmica é pertinente em várias áreas de atuação, quando pensamos na intervenção em serviços de saúde este ponto se torna mais delicado. Na discussão dos grupos constatou-se que os cursos de graduação pouco contemplam disciplinas que abordam assuntos que envolvem o SUS:

Tanto na turma em que eu me formei como os demais estudantes que vieram fazer estágio no São Pedro, até hoje, não tem na sua formação uma discussão sobre os serviços públicos. [PEF3A]

Tudo que eu aprendi sobre saúde e saúde coletiva, saúde publica, sobre SUS, sobre Educação Física na saúde, eu fui aprender depois da faculdade, em especialização, em discussões, em grupos de discussão da educação física na saúde. Foi quase como entrar por acaso numa área que eu me deparei, gostei muito assim, me encantei, e aí fui atrás. [PEF5A]

Essa área da saúde, voltada pra saúde pública não tem nada na formação acadêmica, a não ser uma única cadeira de saúde coletiva que eu já cursei. [PEF6B]

Seja a abertura das universidades, do curso para as pessoas, pra os universitários vivenciarem essa área, porque eu vejo que é muito fechadinho assim, como é que tu vai chegar, eu nem sabia o que era um CAPS, não sabia como funcionava o sistema de saúde da minha cidade, o que era UBS(...)Tudo bem, cada um tem sua escolha, cada um vai para a ênfase que quer, mas é importante ter essa possibilidade. [PEF7B]

E depois disto eu fiz algumas cadeiras eletivas na faculdade, uma eu acho (...) que tem uma trajetória na saúde coletiva. [PEF8B]

Esta temática em questão tem muitos pontos de tensão. Ao analisar detalhadamente o currículo dos cursos de graduação em EF, certamente encontra-se uma série de disciplinas que são da área da saúde. No entanto, seu cunho é de ordem curativa e centrado na doença, sem dialogar com a lógica do SUS e as práticas de Saúde Coletiva.

Para definir Saúde Coletiva utilizou-se o conceito de Carvalho e Ceccim (2009): “um campo de produção de conhecimento e de intervenção profissional especializada, mas também interdisciplinar, onde não há disputa por limites precisos ou rígidos entre as dife- rentes escutas ou diferentes modos de olhar, pensar e produzir saúde. Todas as práticas de saúde orientadas para os modos de andar a vida, melhorando as condições de existência das pessoas e coletividades demarcam intervenção e possibilidades às transformações nos modos de viver, trabalham com promoção da saúde, prevenção de doenças e agravos, ações de reabilitação psicossocial e proteção da cidadania, entre outras práticas de proteção e recuperação da saúde" (CARVALHO E CECCIM, 2009, p. 138).

Mattos (2004) aponta a importância da formação de profissionais de saúde con- 
templar o cuidado integral do indivíduo, sendo a integralidade uma das diretrizes da atenção em saúde no SUS. Para uma formação deste tipo, é necessário que o aluno, desde a graduação tenha contato com diferentes sujeitos, necessidade e realidade de vida. Busca-se superar de atividade e/ou procedimentos do cuidado em saúde.

Fragelli e Shimizu (2013) apontam na pesquisa que realizaram a partir de publicações científicas no período de 2000 a 2010, que encontraram apenas três trabalhos que abordam as competências do PEF para atuar na saúde. Esta situação certamente contribui para o distanciando dos PEF com este campo de intervenção.

Anjos e Duarte (2009) analisaram currículos com intuito de verificar o objeto de cursos, as disciplinas relacionadas com a saúde, a existência de disciplinas de Saúde Coletiva e Saúde Pública e, também, ver se havia disciplinas de estagio nos serviços públicos de saúde. O que eles constataram é que as únicas disciplinas que aparecem em todos os currículos pesquisados têm enfoque curativo ou prescritivo, não sendo contempladas ou priorizadas disciplinas como as de Saúde Coletiva ou Saúde Pública. A pesquisa também revelou que nenhuma instituição de ensino tinha institucionalizado o estágio em serviços público de saúde. Ambos também afirmam que este contexto contribui para que os profissionais de EF sintam-se incapazes de atuar neste campo. Essa reflexão pode justificar uma fala que emergiu no grupo:

Então não me envolvi com prontuários e essas coisas; não me envolvi mesmo. Por eu não ter experiência, eu achei melhor eu ir lá fazer uma prática normal, como eu faço no parque, sem me envolver com outras questões, por questões de inexperiência mesmo. E de falta de conhecimento também. [PEF10B]

[PEF10B]: Não sou um trabalhador da saúde, então realmente eu fiz aquilo que fiz a minha vida inteira que não serviu com certeza, não serviu, né.

[PEF7B]: Ou sim?

[PEF10B]: Ou sim, ou não, né. Não sei, mas assim, pode ter trabalhado? Pode, mas de uma maneira diferente.

Essas afirmações causaram perceptível incômodo nos outros participantes que reagiram contrapondo, questionando e, após, acolhendo a colega. Uma forma de contrapor foi reafirmar-se como profissional de saúde:

Mas eu me coloco como um trabalhador de saúde, não só como um professor de educação física do serviço. Mas eu acho que é interessante a gente poder ampliar, sei lá como, se colocar como trabalhador da saúde. Se colocar como um profissional de saúde, querer construir outras possibilidades, se tem um viés romântico assim da nossa parte, é isto que a gente almeja, mas nem sempre é o que a gente vai encontrar. [PEF11B] 
Mas eu acho que é interessante a gente poder ampliar, sei lá como, se colocar como trabaIhador da saúde. Se colocar como um profissional de saúde, querer construir outras possibilidades, se tem um viés romântico assim da nossa parte, é isto que a gente almeja, mas nem sempre é o que a gente vai encontrar. Até pra justificar nossa inserção no campo da saúde é importante se colocar como trabalhador de saúde, não só especifico como educador físico. Se envolver no serviço como um todo. [PEF6B]

Já está evidenciada a importância da atividade física para a prevenção de doenças crônicas degenerativas, no entanto, um PEF que se coloca como trabalhador de saúde precisa propor ações que contemplem a promoção de saúde e qualidade de vida da população. As diversas categorias de movimento humano compõe um patrimônio cultural da humanidade, chamada de cultura do movimento (TANI, 2007). É papel do PEF é ampliar o acesso, de todos os níveis da população, à cultura do movimento, ao lazer desenvolvendo nas pessoas que atende uma postura crítica e autônoma que poderá escolher, disseminar, transformar este patrimônio cultural que é movimento humano.

Andrade, Costa, Garcia e Florindo (2014) discutem a formação do bacharel em EF em relação a saúde no Brasil, eles apontam uma questão importante para pensar a formação para o SUS ao considerar que o aluno que ingressa no curso já tem uma imagem do SUS que muitas vezes não está relacionada com a realidade, somado a isto, tem-se poucas pesquisas que explorem a competência necessária para atuar na saúde. Diante deste contexto, os autores propõe temas a serem trabalhados para melhorar a formação do PEF: como lidar com grupos que não escolheram realizar atividade física; ampliar as disciplinas na área da Saúde Pública, numa visão ampliada de saúde; incentivar estágio em espaços não tradicionais da EF; saír da prescrição individualizada para a intervenção comunitária, assim como, mudar o foco da avaliação física para a avaliação da ação, políticas, programas; estímulo ao trabalho multiprofissional e interdisciplinar, fomentar que o PEF compreenda o contexto de vida da pessoa antes de intervir; saber sobre Educação Permanente, Promoção de Saúde, matriciamente visando ampliar suas estratégias de ação.

Para isto, os autores reforçam a importância atravessarem o ensino, a pesquisa e a extensão e serem contemplados no Projeto Político do Curso.

\section{CONSIDERAÇÕES FINAIS}

Este estudo não ambicionou chegar a um lugar definido, um ponto certo e seguro sobre a identidade do PEF na saúde pública determinando um modelo único de formação e intervenção para esta área. Assumir uma postura que defina como deve ou não deve ser a formação da educação física e recorrer em falhas já cometidas, quando se cria cursos voltados a saúde com uma base de conhecimento biologicista.

A formação profissional vem sendo repensada em todas as áreas da saúde, questões como que profissional o SUS precisa são frequentes nos diversos cursos de graduação, sendo um desafio coletivo. 
A saúde pública tem sido um campo de atuação em expansão e necessita de profissionais melhor preparados para que esta área de intervenção seja ocupada com especificidade e qualidade.

Os avanços na formação e intervenção dos PEF na rede pública de saúde são perceptíveis, um exemplo é a ampliação dos postos de trabalho no SUS nos últimos anos.

Muitas discussões são feitas sobre o que é a $E F$, muitos fundamentos já estão estabelecidos para as áreas como educação, condicionamento físico, lazer, entre outras. Todavia, considerando o SUS com suas políticas de atenção, pouco está definido. E os trabalhadores que constroem cotidianamente este fazer, por meio de vivências, reflexões, buscam pistas que os orientem e, algumas vezes, definam o que compete ao EF.

A Residência Multiprofissional em Saúde tem sido uma estratégia de educação permanente que amplia os pontos de chegada, tanto nos serviços como na área de conhecimento da EF. Também se mostra como uma possibilidade de encontros com outras áreas e dentro do seu próprio núcleo, permitindo o "borramento" do limite de cada disciplina que compõe o cotidiano do trabalho.

A formação na graduação e na pós-graduação é uma questão importante para a mudança de práticas no SUS, mas deve ser uma formação para além da técnica, uma formação onde o que se proporá ao aluno é uma nova concepção de sociedade e de sujeito. Onde o trabalhar pode romper com a lógica de rendimento físico e com a busca de parâmetros fisiológicos que pouco significam para a realidade de vida dos sujeitos e dos territórios que atendemos. Esta pesquisa não se encerra aqui e busca lançar desafios para que sejam pensadas as questões aqui apresentadas.

\section{REFERÊNCIAS}

ANDRADE, D. R.; COSTA, E. F.; GARCIA, L. M. T.; FLORINDO, A. A. Formação do bacharel em educação física frente a situação de saúde no Brasil. In: BENEDETTI, T. R. B. et al. A formação do profissional de educação física para o setor saúde. Florianópolis; Postmix, p. 87-107, 2014.

ANJOS, T. C. dos; DUARTE, A. C. G. de O. A Educação Física e a Estratégia de Saúde da Família: formação e atuação profissional. Physis Revista de Saúde Coletiva, Rio de Janeiro, v. 19, n. 4, p. 1127-1144, 2009.

ANTUNES, A. C. A dimensão prática na preparação profissional em educação física: concepção e organização acadêmica. 2012. 265

f. Tese (Doutorado) - Departamento de Faculdade de Educação Física, Universidade Estadual de Campinas, Campinas, 2012.

AURÉLIO. Novo Dicionário Aurélio da Língua Portuguesa. 3. ed. Positivo Informática Ltda, 2004.

BARDIN, L. Análise de Conteúdo. São

Paulo: Ed. Persona, 2004.

BENEDETTI, T. R. B.; BORGES, L. J. Vivência acadêmica e proximidade prática na saúde. In: BENEDETTI, T. R. B. et al. A formação do profissional de educação física para o setor saúde. Florianópolis; Postmix, p. 51-66, 2014. BRACHT, V. A constituição das teorias pedagógicas da educação física. 
Cadernos Cedes, Campinas, ano XIX, no 48, p. 69-88, Agosto/99.

BRASIL. LEI No 9.696, DE 1 DE

SETEMBRO DE 1998. Dispõe sobre a regulamentação da Profissão de Educação Física e cria os respectivos Conselho Federal e Conselhos Regionais de Educação Física. Brasília: Diário Oficial da União, 1998.

BRASIL. Ministério da Saúde. Secretaria de Atenção à Saúde/ DAPE. Saúde Mental no SUS: o centro de atenção psicossocial... Brasília, DF: Ministério da Saúde, 2004.

CARVALHO, Y. M. de; CECCIM, R. B. Formação e Educação em Saúde: aprendizados com a Saúde Coletiva. In: CAMPOS, G. W.de S; MINAYO, M. C. de $S$; AKERMAN, M; DRUMOND Júnior, M; CARVALHO, Y. M. de. Tratado de Saúde Coletiva. $2^{\mathrm{a}} \mathrm{Ed}$. Rio de Janeiro; Hucitec, p. 137-170, 2009.

DARIDO, S. C. Teoria, Prática e Reflexão na Formação Profissional em Educação Física. In: V SIMPÓSIO PAULISTA DE EDUCAÇÃO FÍSICA. Motriz, v. 1, n. 2, p. 124-128, Dezembro/1995.

CONFEF. Conselho Federal de Educação Física (Brasil). RESOLUÇÃO CONFEF $\mathbf{n}^{\mathbf{0}} \mathbf{0 5 6} / \mathbf{2 0 0 3}$. Rio de Janeiro, 2003.

CONFEF. Conselho Federal de Educação Física (Brasil). RESOLUÇÃO CONFEF $\mathbf{n}^{\mathbf{0}} \mathbf{0 4 6} / \mathbf{2 0 0 2}$. Rio de Janeiro, 2002.

CREF/RS. Conselho Regional de Educação Física (Rio Grande do Sul). Registro de Graduado. Disponível em: < http://www. crefrs.org.br/registro/reg_graduado. asp >. Acesso em: 23 jun. 2012.

DIAS, S.F.; ROCHA, C. F. Saúde Sexual e Reprodutiva de Mulheres Imigrantes Africanas e Brasileiras: um estudo qualitativo. Estudos OI 32. Portugal: Paulinas Editora, Junho 2009.
FRAGELLI, T. B. O.; SHIMIZU, H. E. Prospecções para desenvolvimento de políticas públicas de formação de profissionais de saúde a partir da análise do cenário brasileiro de competências. Physis: Revista de Saúde Coletiva, v. 23, n. 1, p. 197-208, 2013.

FREIRE, E. dos S; VERENGUER, R. de C. G; REIS, M. C. da C. Educação Física: Pensando a profissão e a preparação profissional. Revista Mackenzie de Educação Física e Esporte, São Paulo, v. 1, n. 1, p. 39-46, 2002.

GANCZ, Ricardo. O ensino da história da educação física no Brasil: ainda seguimos uma visão linear?. In: CONGRESSO LUSO-BRASILEIRO DE HISTÓRIA DA EDUCAÇÃO, 6., 2006, Uberlandia. Anais do VI Congresso Luso-Brasileiro de História da Educação. Uberlandia: UFU, 2006. p. 1978-1998.

LERVOLINO, S. A.; PELICIONI, M. C. F. A Utilização do Grupo Focal como Metodologia Qualitativa na Promoção da Saúde. Rev. Esc. Enf. USP, São Paulo, v. 32, n. 5, p.115-121, jun. 2001.

MATTA, G. C; MOROSINI, M. V. G. Atenção Primária em Saúde. In: PEREIRA, Isabel Brasil; LIMA, Júlio Cesar França. Dicionário da Educação Profissional em Saúde. 2. ed. Rio de Janeiro: EPSJV, 2009. Disponivel em: <http://www.epsjv.fiocruz.br/ dicionario/verbetes/ateprisau.html $>$. Acesso em: 30/10/2014.

MATTOS, R. Integralidade como eixo da formação de profissionais de saúde. Revista Brasileira de Educação Médica. 2004, v. 28, n. 2, p. 91-92.

MENDES, M. F. M. Bricolagem da Educação Física: intervenções feitas de ciência e arte na rede pública de saúde. Porto Alegre: UFRGS, 2013. Trabalho de 
Conclusão de Especialização. Curso de Especialização em Práticas Pedagógicas para Educação em Serviços de Saúde. Faculdade de Educação, Universidade Federal do Rio Grande do Sul, Porto Alegre, 2013.

MERHY, E. E. Saúde: a cartografia do trabalho vivo. São Paulo: Hucitec, 2002 OLIVEIRA, Vitor Marinho de. O que é Educação Física. 9. ed. São Paulo: Brasiliense, 1983

STEINHILBER, J. Licenciatura e/ou Bacharelado: opções de graduação para intervenção profissional. Revista EF. Rio de Janeiro, Ano VI, n. 19, p. 19-20, março 2006.
TANI, G. Avaliação das condições do ensino de graduação em educação física: garantia de uma formação de qualidade. Revista Mackenzie de Educação Física e Esporte, São Paulo, v. 6, n. 2, p.55-70, 2007.

TOJAL, J. B. A.. Formação de profissionais de educação física e esportes na América Latina. Movimento \& Percepção, Espírito Santo de Pinhal, v.5, n. 7, p. 2-54, jul/dez. 2005.

VERENGUER, R.de C. G.. Intervenção profissional em Educação Física: expertise, credencialismo e autonomia. Motriz, Rio Claro, v. 2, n. 10, p. 123134, maio/ago. 2004.

PHYSICAL EDUCATION AND THE PUBLIC HEALTH CARE SYSTEM: dilemmas, possibilities and challenges between the formation and the intervention

\begin{abstract}
The aim of this research was to identify and analyze the activities performed by physical education professionals (PEF) in the public health services. Methodology: the focus group technique as used, with the participation on eleven PEF. Results: the PEF enroll in health services without knowledge of the area, they do not recognize the tools that offered them for graduate work and believe that the daily work or training postgraduate were the strategies that gave them the ability to work in the SUS. Considerations: the research identified that there is a gap between the formation of the PEF and the reality of professional practice that meets the guidelines and requirements of the SUS. Training must overcome the hegemonic biological model focuses purely technical, propounding a reflection of reality and a new conception of health, society and subject.
\end{abstract}

Keywords: Physical Education; Health Care; Professional Competence 
V. $26, n^{\circ} 43$, dezembro/2014

EDUCACIÓN FÍSICA Y LA RED DE SALUD PÚBLICA: dilemas, posibilidades y desafíos entre la formación y la intervención

\section{RESUMEN}

El objetivo de esta investigación fue identificar y analizar las actividades realizadas por los profesionales de Educación Física (PEF) en el campo de la Salud Pública e investigar como la formación influencia en su práctica profesional. Metodología: se utilizó la técnica de Grupo Focal con la participación de once profesionales de Educación Física vinculados a la red pública de salud. Resultados: emergieron dos categorías: una dice respeto a la formación profesional y la otra a la inserción de los PEF en el campo de la Salud Pública. Consideraciones: La pesquisa identifico que existe un hueco entre la formación del PEF y a la realidad de la practica profesional que atienda a las directrices y a las necesidades del SUS. La formación debe superar el modelo hegemónico biológico, centrado puramente de la técnica, proponiendo al alumno una reflexión crítica de la realidad social y una nueva concepción de salud, sociedad y de sujeto.

Palabras clave: Educación Física; Atención a la Salud; Cualificación Profesional

Recebido em: agosto/2014 Aprovado em: novembro/2014 